\title{
The Duties of Dermatologists During COVID-19 Pandemic in Turkey: Results of a Nationwide Survey
}

\author{
Muazzez Cigdem Oba, (1) Kursat Goker \\ Department of Dermatology and Venereology, Health Sciences University, Sancaktepe Sehit Prof. Dr. Ilhan Varank Training and \\ Research Hospital, Istanbul, Turkey
}

\begin{abstract}
Objectives: The coronavirus disease 2019 (COVID-19) has led to a reorganization of health services throughout many countries. In this study, we aimed to get an overview of the duties of the dermatologists during COVID-19 pandemic in Turkey. In light of the results, we aimed to determine the aspects of Turkish dermatology practice which might require innovation.

Methods: Dermatologists across Turkey were asked to fill in an online 11-item questionnaire survey, investigating their duty/duties (dermatology outpatient and inpatient clinics, pandemic outpatient and inpatient clinics, emergency, etc.) month by month during March-June 2020.

Results: A total of 217 dermatologists participated in the survey. Vast majority (91-98\%) of the participants reported that they performed dermatology outpatient visits. While $41.5-56.2 \%$ of participants were redeployed to pandemic inpatient clinics, $12.9-29 \%$ were mobilized to pandemic outpatient clinics. Each month, at least $90 \%$ of the residents that participated in the questionnaire reported that they were recruited to pandemic inpatient clinics.

Conclusion: As the impact of COVID-19 pandemic is ongoing in Turkey, these data should be taken into consideration to rapidly implement new measures in Turkish dermatology practices such as a referral system for dermatology outpatient visits to equitably distribute dermatology services, widespread use of telemedicine, and virtual educations of residents.

Keywords: Coronavirus; dermatology; pandemic.

Please cite this article as "Oba MC, Goker K. The Duties of Dermatologists During COVID-19 Pandemic in Turkey: Results of a Nationwide Survey. Med Bull Sisli Etfal Hosp 2021;55(4):457-461".
\end{abstract}

$\mathrm{T}$ he coronavirus disease 2019 (COVID-19) caused by the severe acute respiratory syndrome coronavirus 2 has led to a reorganization of health services throughout many countries. Junior doctors as well as physicians of various specialties were recruited to intensive care units, COVID-19 wards, emergency units, etc. ${ }^{[1-5]}$ In Turkey, many hospitals mobilized physicians from all of specialties to take part in the care of patients with COVID-19, including the authors.[6] In addition, non-emergent outpatient visits were suspended in many countries. ${ }^{[7-9]}$

In this study, we aimed to get an overview of the role of the dermatologists during COVID-19 pandemic in Turkey. In light of the results, we aimed to determine the aspects of Turkish dermatology practice which might require innovation.

Address for correspondence: Muazzez Cigdem Oba, MD. Dermatoloji ve Zührevi Hastalıklar Anabilim Dalı, Saglik Bilimleri Universitesi, Sancaktepe Sehit Prof. Dr. Ilhan Varank Egitim ve Arastirma Hastanesi, Istanbul, Turkey

Phone: +90 5301426541 E-mail: muazzez.oba@istanbul.edu.tr

Submitted Date: March 25, 2021 Accepted Date: April 08, 2021 Available Online Date: December 29, 2021

${ }^{\circ}$ Copyright 2021 by The Medical Bulletin of Sisli Etfal Hospital - Available online at www.sislietfaltip.org

OPEN ACCESS This is an open access article under the CC BY-NC license (http://creativecommons.org/licenses/by-nc/4.0/). 


\section{Methods}

Dermatologists across Turkey were asked to fill in an online 11-item questionnaire survey, composed on Google Forms. The survey was distributed to the dermatologists across Turkey through email groups, social media, and WhatsApp groups. The participants were allowed to respond the questionnaire from beginning of July 2020 till August 15.

The questions included the age and sex of the participants, their affiliation and academic degree, the city where they worked, and their duty/duties (dermatology outpatient and inpatient clinics, pandemic outpatient and inpatient clinics, emergency, etc.) month by month during MarchJune 2020. In the last two questions, daily number of dermatology outpatients examined and number of monthly shifts in pandemic inpatient clinics were asked. All questions were obligatory.

The study was approved by both the local review board (approval number: 116.2017.183 approval date: July 02, 2020) and Turkish Ministry of Health.

\section{Statistical Analysis}

Descriptive statistics were reported as mean, minimum, and maximum for continuous data; as count and percentage for categorical data. Chi-square test and Bonferroni correction were used to analyze categorical data and make multiple comparisons between groups. Statistical analyses were performed using the Statistical Package for the Social Sciences (SPSS, Chicago, IL, USA) version 21.0. $\mathrm{P}<0.05$ was considered statistically significant.

\section{Results}

\section{Descriptive Statistics}

A total of 217 responses were obtained from dermatologists across Turkey. Dermatologists of all ages, from residents to senior dermatologists, participated in the survey (age range: $27-70$ ). Majority of them (68.7\%) were women. Vast majority of the participants were working in governmental hospitals including research and training hospitals (28.1\%) and public hospitals ( $25.3 \%)$ followed by university hospitals (24.4\%) and private hospitals (13.8\%). Although respondents were from nearly all cities of Turkey, dermatologists from three biggest cities of Turkey dominated (34.6\%, 10.1\%, and 6\% for Istanbul, Ankara, and Izmir, respectively). Academic degrees of participants were specialist $(66.4 \%)$, resident $(18.9 \%)$, associate professor $(8.3 \%)$, and professor (6.5\%). Demographic data of participants are shown in Table 1.
Table 1. Demographic data of participants

\begin{tabular}{lc}
\hline Parameters & Number (\%) \\
\hline Sex & \\
Male & $68(31.3)$ \\
Female & $149(68.7)$ \\
Age & \\
27-30 & $54(24.9)$ \\
$31-40$ & $88(40.6)$ \\
$41-50$ & $41(18.9)$ \\
$51-60$ & $27(12.4)$ \\
>60 & $7(3.2)$ \\
Affiliation & \\
Public hospital & $55(25.3)$ \\
Public research and training hospital & $61(28.1)$ \\
University hospital & $53(24.4)$ \\
Private hospital & $30(13.8)$ \\
Private practice & $12(5.5)$ \\
Public city hospital & $6(2.8)$ \\
Academic degree & \\
Resident & $41(18.9)$ \\
Specialist & $144(66.4)$ \\
Associate professor & $18(8.3)$ \\
Professor & $14(6.5)$ \\
Region & \\
Marmara & $96(44.2)$ \\
Aegean & $22(10.1)$ \\
Black sea & $20(9.2)$ \\
Central Anatolia & $43(19.8)$ \\
Sast Anatolia & $7(3.2)$ \\
Mediterranean & $17(7.8)$ \\
\hline & $12(5.5)$ \\
\hline
\end{tabular}

\section{Dermatology Outpatient Visits}

Vast majority of the participants reported that they performed dermatology outpatient visits. In March and June, $98 \%$ of participants worked in outpatient clinics. The percentage was reduced to $91 \%$ and $93 \%$ in April and May, respectively. Figure 1 shows distribution of participants

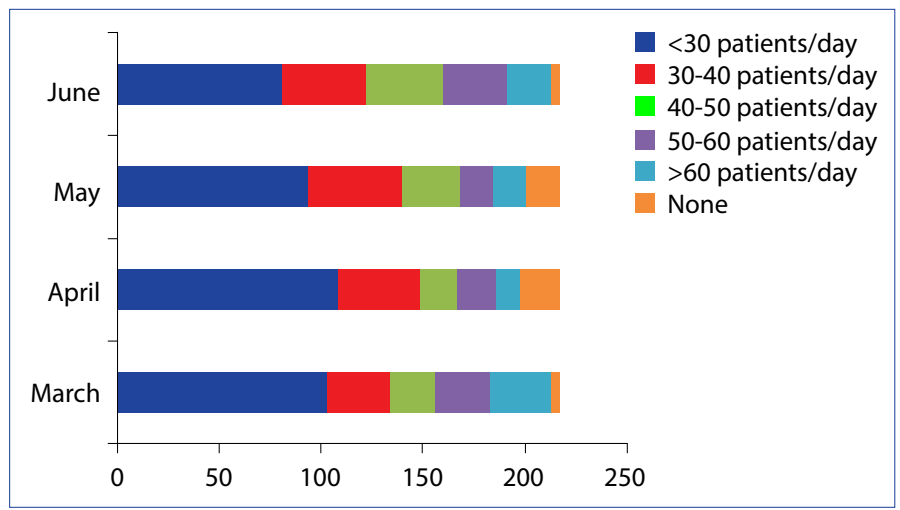

Figure 1. Monthly distribution of participants working in dermatology outpatient clinics and number of daily visits performed. 
working in dermatology outpatient clinics and number of daily visits performed, on monthly basis.

\section{Dermatology Inpatient Clinics}

In March, $21.2 \%$ of participants stated that they worked in dermatology inpatient clinics. This percentage dropped to $12.4 \%$ in April, though not significantly $(p=0.06)$. In May and June, $17 \%$ and $24.4 \%$ of participants stated that they worked in dermatology wards. A statistically significant difference was detected between April and June $(p=<.0 .001)$.

\section{Pandemic Inpatient Clinics}

In March, $42.4 \%$ of the participants were recruited to pandemic inpatient clinics. This percentage significantly increased in April as $56.2 \%$ of dermatologists stated that they worked in pandemic inpatient clinics $(p=0.001)$. In May and June, $50.2 \%$ and $41.5 \%$ of participants reported working in pandemic inpatient clinics. Statistical difference was also found in the percentage of participants caring for COVID-19 inpatients between April and June $(p=<0.001)$. Most of the participants who were recruited in pandemic inpatient clinics indicated having one to three shifts per month. The monthly distribution of participants involved in pandemic inpatient care along with number of monthly shifts is shown in Figure 2. Participants recruited in pandemic inpatient clinics during March-June 2020 were all among public staff of research and training hospitals, public hospitals, and university hospitals. Participants working in private hospitals or private practice indicated that they did not take part in pandemic inpatient care except for two participants working in private hospital who stated working in pandemic inpatient care in April. Analysis according to academic degree revealed residents and specialist to form the vast majority of participants recruited to pandemic inpatient clinics. During four months, only $2.8-6.5 \%$ of participants recruited to COVID wards were associate professor and professors. However, each month, at least $90 \%$

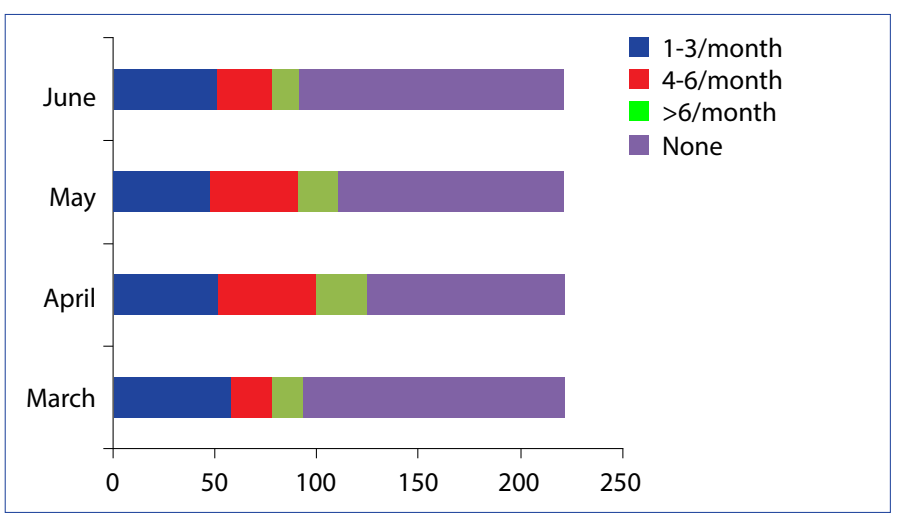

Figure 2. Monthly distribution of participants involved in pandemic inpatient care and number of monthly shifts. of the residents that participated in the questionnaire reported that they were recruited to pandemic inpatient clinics. During April 2020, 26.9\% of participants reported that they worked solely in pandemic inpatient clinics. This ratio decreased to $17.6 \%$ and $3.1 \%$ of participants in May and June, respectively.

\section{Pandemic Outpatient Clinics}

Pandemic outpatient clinics were created throughout Turkey, to function as COVID-19 screening outpatient clinics. Patients with fever, cough, and dyspnea were firstly examined in these clinics so as to isolate these potential cases from other patients seeking medical care. In March, 12.9\% of respondents reported that they worked in pandemic outpatient clinics. A surge in the number of participants (29\%) that worked in COVID-19 screening outpatient clinics was seen in April, with a significant statistical difference between March and April ( $p=<0.001)$. In May and June, $24.4 \%$ and $15.2 \%$ of participants reported that they worked in pandemic outpatient clinics. Statistically, the difference between March and May $(p=<0.001)$ and April and June ( $p=<0.001)$ was also significant.

\section{Discussion}

This study demonstrated that majority of the dermatologists working in Turkey were actively involved in the care of COVID-19 patients as well as pursuing dermatology clinical practices. Considering there were 2351 actively working dermatologists in Turkey during the study period, results of our survey with 217 participants have a 95\% confidence interval and a margin error of $6.3 \%$.

Across the globe, the COVID-19 pandemic has had its impact on the dermatology practice. Number of patients seen in outpatient clinics and number of surgeries performed significantly decreased. ${ }^{[8,10,11]}$ In various countries, dermatologists were involved in the fight against COVID-19 pandemic. In the US, 31.9\% of dermatology residents were redeployed to non-dermatology services including emergency department, inpatient wards, and intensive care units. ${ }^{[12]}$ Dermatology staff of Penn Medicine, US, was redeployed to assess and manage COVID-19 results of their health care system's emergency department and ambulatory test sites. ${ }^{[13]}$ In Italy, Spain, and UK, dermatologists were relocated to care for COVID-19 patients. ${ }^{[11,14,15]}$ In India, dermatologists were not involved in the primary care of COVID cases, however, outpatient clinics were closed in many hospitals and dermatology wards were converted to COVID wards. ${ }^{[16]}$ Hospitalizations in dermatology inpatient clinics were completely or partially suspended in many countries..$^{[7,16,17]}$ Similarly, our survey revealed that the number of participants that worked in dermatology inpatient 
clinics was significantly reduced in April, as compared to June $(p=<0.001)$.

InTurkey, the first confirmed COVID-19 case was announced on March 11, 2020. According to the data provided by the Turkish Ministry of Health, the number of confirmed COVID-19 cases was 198,284 from March 11, 2020, till June $28,2020{ }^{[18]}$ Shortly after the first case, Turkish government applied a partial lockdown, closed schools and restaurants, and restricted domestic and abroad travels. However, at June 1, several restrictions were reduced, considered as "normalization steps."

Kutlu et al. reported a significant decrease in the number of dermatology outpatient visits immediately after the beginning of COVID-19 pandemic in Turkey by comparing the average number of patients examined 10 days before and 10 days after the first COVID-19 case in Turkey. The study showed that, despite the sharp decrease, the number of daily visits did not drop under 39 and the most common five diagnoses were all non-emergent diagnoses such as acne, warts, and seborrheic dermatitis. ${ }^{[19]}$ Another study by Cengiz et al. revealed 390 presentations to one dermatology outpatient clinic in Istanbul during March 11-18, 2020.[20] Tanacan et al. reported a significant decrease (from 1165 to 717) in number of hospital admissions of a tertiary dermatology clinic by comparing the number of admissions during March-May 2019 to that of 2020. ${ }^{[21]}$ A multicenter study conducted between January 12, 2020, and May 12, 2020, found $77 \%$ decrease in daily hospital applications. ${ }^{[22]}$ However, our data showed that a substantial number of dermatology outpatient clinic visits were performed during March-June 2020 despite the pandemic. This finding does not contradict the literature and it is attributable to the fact that dermatology outpatient clinics were overcrowded in the pre-pandemic period in Turkey. In recent years, Turkish health policies have been aiming to increase patient satisfaction. ${ }^{[23]}$ During COVID-19 pandemic, measures should have been taken to suspend all non-emergent visits ${ }^{[24]}$ to limit both patientpatient and patient-physician COVID transmission. However, this was not the case in Turkey even during the early pandemic, as our findings have shown that each month, half of dermatologists reported examining more than 30 patients per day. In addition, Turkish health-care system does not require patients to have a referral to make an appointment to dermatologists and vast majority of the busy dermatology outpatient visits performed are non-emergent. During COVID pandemic, the Turkish health ministry has only recommended, but not obliged, the patients to visit their general practitioner before applying to dermatology outpatient clinics. We think this approach, along with the decreased dermatology staff due to redeployment of dermatologists to COVID wards, might have led to significant delays in emer- gent dermatology visits. In addition, restrictions for elderly ( $>65$ years) people such as the ban of using public transport might also have contributed to uneven distribution of emergent dermatology services.

Considering that dermatologists are physicians first, they may be recruited to COVID wards, triage stations, and even ICUs, if need occurs. ${ }^{[15,25,26]}$ Our study showed that $41.5-56.2 \%$ of participants were redeployed to pandemic inpatient clinics. Across 4 months, the percentage of participants that were mobilized to COVID inpatient clinics and outpatient clinics changed. These changes were in accordance with the rate of COVID cases in Turkey as the first case was in March 11, the rapid rise in April and May, and a slowing down in June. Of note, a strikingly high percentage of at least $90 \%$ of residents that participated in the questionnaire stated that they were recruited to pandemic inpatient clinics during March-June 2020. This might have significantly impaired specialty education of dermatology residents in Turkey. E-learning programs were created for medical students across all universities in Turkey. ${ }^{[27]}$ To overcome the disruption in resident education, implementation of virtual lectures and supervised telemedicine visits that incorporate residents should also be planned, as accomplished in various countries. ${ }^{[8,28-30]}$

Limitations of our study include the recall bias, undercoverage of associate professors and professors, and the lack of a question asking whether the redeployment was volunteered or of necessity. However, all of dermatologists that were redeployed to COVID-19 inpatient and outpatient clinics were staff of public hospitals, except two. This finding supports the assumption that the mobilization of dermatologists was mostly because of health policies.

\section{Conclusion}

Our findings indicate that the COVID-19 pandemic has significantly affected the daily clinical practice of dermatologists in Turkey. Considering the ongoing impact of COVID-19 pandemic in many countries including Turkey, these data should be taken into consideration to rapidly implement new measures such as a referral system for dermatology outpatient visits to equitably distribute dermatology services, widespread use of telemedicine, and virtual educations of residents.

\section{Disclosures}

Ethics Committee Approval: This study was approved by the ethşcs committee of Health Sciences University, Süreyyapasa Chest Diseases and Thoracic Surgery Research and Training Hospital (no: 116.2017.183, approval date: July 2, 2020).

Peer-review: Externally peer-reviewed.

Conflict of Interest: None declared. 
Authorship Contributions: Concept - K.G.; Design - M.C.O., K.G.; Supervision - K.G.; Materials - M.C.O., K.G.; Data collection \&/or processing - K.G.; Analysis and/or interpretation - M.C.O.; Literature search - M.C.O.; Writing - M.C.O., K.G.; Critical review - M.C.O.

\section{References}

1. Coughlan C, Nafde C, Khodatars S, Jeanes AL, Habib S, Donaldson E, et al. COVID-19: lessons for junior doctors redeployed to critical care. Postgrad Med J 2021;97:188-91. [CrossRef]

2. Shipchandler TZ, Nesemeier BR, Schmalbach CE, Ting JY. Otolaryngologists' role in redeployment during the COVID-19 pandemic: a commentary. Otolaryngol Head Neck Surg 2020;163:94-5.

3. Lim C, De Silva I, Moussa G, Islam T, Osman L, Malick H, et al. Redeployment of ophthalmologists in the United Kingdom during the Coronavirus Disease Pandemic. Eur J Ophthalmol 2021;31:2268-74.

4. Albano D, Bruno A, Bruno F, Calandri M, Caruso D, Clemente A, et al; Young SIRM Working Group. Impact of coronavirus disease 2019 (COVID-19) emergency on Italian radiologists: a national survey. Eur Radiol 2020;30:6635-44. [CrossRef]

5. Malgor RD, Sobreira ML, Mouawad NJ, Johnson AP, Wohlauer MV, Coogan SM, et al. Brazilian vascular surgeons experience during the coronavirus (COVID-19) pandemic. Vascular 2021;29:451-60.

6. Göker K. COVID-19 ve Dermatoloji. Pandemi Yatan Hastaların Dermatolojik Yönetimi. In: Yiyit N, Bakan N, Güven Ş, Uğur M, Demir S, Temiz SG, editors. COVID-19 ve Pandemi Hastanesine Dönüşüm. 1st ed. Istanbul: Galenos Press; 2020. p. 295-9.

7. Patrizi A, Bardazzi F, Filippi F, Abbenante D, Piraccini BM. The COVID-19 outbreak in Italy: Preventive and protective measures adopted by the Dermatology Unit of Bologna University Hospital. Dermatol Ther 2020;33:e13469. [CrossRef]

8. Abedini R, Ghandi N, Lajevardi V, Ghiasi M, Nasimi M. Dermatology department: what we could do amidst the pandemic of COVID-19? J Dermatolog Treat 2020:1-2. [CrossRef]

9. Bhargava S, Sarkar R. Impact of COVID-19 pandemic on dermatology practice in India. Indian Dermatol Online J 2020;11:712-9.

10. Litchman GH, Rigel DS. The immediate impact of COVID-19 on US dermatology practices. J Am Acad Dermatol 2020;83:685-6.

11. Radi G, Diotallevi F, Campanati A, Offidani A. Global coronavirus pandemic (2019-nCOV): implication for an Italian medium size dermatological clinic of a II level hospital. J Eur Acad Dermatol Venereol 2020;34:e213-4. [CrossRef]

12. Stewart CR, Lipner SR. Experiences of resident dermatologists during the COVID-19 pandemic: A cross-sectional survey. Dermatol Ther 2021;34:e14574. [CrossRef]

13. Ran NA, Samimi SS, Zhang J, Chaiyachati KH, Mallozzi CP, Hanson CW 3rd, et al. Redeployment of dermatologists during COVID-19: Implementation of a large-scale, centralized results management infrastructure. J Am Acad Dermatol 2020;83:974-6. [CrossRef]

14. Cerro PA, Palma AM, Navarro-Bielsa A, Gilaberte Y. RF - organization of a dermatology department during the COVID-19 pandemic. Actas Dermosifiliogr (Engl Ed) 2020;111:781-2. [CrossRef]

15. Walsh S, Creamer D. A very peculiar practice: dermatology in the era of COVID-19. Br J Dermatol 2020;183:940-1. [CrossRef]
16. Kumar S, Bishnoi A, Vinay K. Changing paradigms of dermatology practice in developing nations in the shadow of COVID-19: Lessons learnt from the pandemic. Dermatol Ther 2020;33:e13472.

17. Białynicki-Birula R, Siemasz I, Otlewska A, Matusiak $Ł$, Szepietowski JC. Influence of COVID-19 pandemic on hospitalizations at the tertiary dermatology department in south-west Poland. Dermatol Ther 2020;33:e13738. [CrossRef]

18. COVID-19 Situation Report Turkey. 2020. Available at: https:// covid19.saglik.gov.tr/Eklenti/37743/0/covid-19-situation-reportv4pdf.pdf?_tag1=1BBBA277D9AA5225230FFF995ECE6DF16684 F1E6. Accessed Dec 14, 2021.

19. Kutlu Ö, Güneş R, Coerdt K, Metin A, Khachemoune A. The effect of the "stay-at-home" policy on requests for dermatology outpatient clinic visits after the COVID-19 outbreak. Dermatol Ther 2020;33:e13581. [CrossRef]

20. Cengiz FP, Emiroglu N, Bahali AG, Dizman D, Taslidere N, Akarslan TC, et al. Which dermatology patients attend to Dermatology Outpatient Clinics during the SARS-CoV-2 outbreak in Turkey and what happened to them? Dermatol Ther 2020;33:e13470. [CrossRef]

21. Tanacan E, Aksoy Sarac G, Emeksiz MAC, Dincer Rota D, Erdogan FG. Changing trends in dermatology practice during COVID-19 pandemic: A single tertiary center experience. Dermatol Ther 2020;33:e14136. [CrossRef]

22. Kartal SP, Çelik G, Sendur N, Aytekin S, Serdaroğlu S, Doğan B, et al. Multicenter study evaluating the impact of COVID-19 outbreak on dermatology outpatients in Turkey. Dermatol. Ther. 2020;33:e14485. [CrossRef]

23. Hamzaoglu N, Türk B. Prevalence of physical and verbal violence against health care workers in Turkey. Int J Health Serv 2019;49:844-61. [CrossRef]

24. Kwatra SG, Sweren RJ, Grossberg AL. Dermatology practices as vectors for COVID-19 transmission: A call for immediate cessation of nonemergent dermatology visits. J Am Acad Dermatol 2020;82:e179-80. [CrossRef]

25. Recalcati S. Cutaneous manifestations in COVID-19: a first perspective. J Eur Acad Dermatol Venereol 2020;34:e212-3. [CrossRef]

26. Murrell DF, Arora G, Rudnicka L, Kassir M, Lotti T, Goldust M. A dermatologist's perspective of the COVID-19 outbreak. Dermatol Ther 2020;33:e13538. [CrossRef]

27. Türsen Ü, Türsen B, Lotti T. Coronavirus-days in dermatology. Dermatol Ther 2020;33:e13438. [CrossRef]

28. Oldenburg R, Marsch A. Optimizing teledermatology visits for dermatology resident education during the COVID-19 pandemic. J Am Acad Dermatol 2020;82:e229. [CrossRef]

29. Patel P, Guzman AK, McLellan B, Blasiak R. Optimizing education for dermatology residents during the COVID-19 pandemic. J Am Acad Dermatol 2020;83:e319-20. [CrossRef]

30. Ladha MA, Lui H, Carroll J, Doiron P, Kirshen C, Wong A, et al. medical student and resident dermatology education in Canada during the COVID-19 pandemic [Formula: see text]. J Cutan Med Surg 2021;25:437-42. [CrossRef] 